\title{
Optimum Injection Pressure of a Cavitating Jet for Introducing Compressive Residual Stress into Stainless Steel*
}

\author{
Hitoshi SOYAMA**, Kazuya NAGASAKA**, Osamu TAKAKUWA** \\ and Akima NAITO** \\ **Department of Nanomechanics, Graduate School of Engineering, Tohoku University, \\ 6-6-01 Aoba, Aramaki, Aoba-ku, Sendai, Miyagi 980-8579, Japan \\ E-mail: soyama@mm.mech.tohoku.ac.jp
}

\begin{abstract}
Introducing compressive residual stress by a cavitating jet into the sub-surface of components used in nuclear power plants can mitigate stress corrosion cracking in these components. Although applying the jet is an effective method for this purpose, it should be used without causing damage to the surface from water jet droplets arising from high-pressure injection of the water jet. Thus, in introducing compressive residual stress, the injection pressure needs to be optimized. In this paper, in order to determine the optimum injection pressure, the residual stress of stainless steel treated by a jet at various injection pressures was measured using an X-ray diffraction method. The injection pressure of the jet was varied from $5 \mathrm{MPa}$ to $300 \mathrm{MPa}$, and the diameter of the nozzle throat of the jet was varied from 0.35 $\mathrm{mm}$ to $2.0 \mathrm{~mm}$. The variation of residual stress with depth was measured by alternating X-ray diffraction measurements with electropolishing. It was revealed that a cavitating jet at an injection pressure of $10 \mathrm{MPa}$ with a nozzle diameter of 2.0 $\mathrm{mm}$ can introduce higher compressive residual stress to deeper into stainless steel compared with a jet at $300 \mathrm{MPa}$ with a nozzle diameter of $0.35 \mathrm{~mm}$ when the downstream pressure of the nozzle was constant.
\end{abstract}

Key words: Residual Stress, Peening, Cavitation, Jet, X-Ray Diffraction

\section{Introduction}

Stress corrosion cracking is a well known fracture phenomenon, caused by tensile stress in a corrosive environment during operation. Since it is difficult to improve a material's resistance to stress corrosion cracking and a corrosive environment, the most effective method to mitigate it is to introduce compressive residual stress into the material surface. In order to do this, a peening technique can be applied. Although some peening techniques such as shot peening, cavitation peening and laser peening are routinely used in practical applications, only cavitation peening and laser peening can be applied for treating some structures, such as those in power plants, because they are of necessity immersed in water.

A peening method using cavitation impacts induced by injecting a high speed water jet into a water filled chamber was proposed ${ }^{(1)}$, its operation was established ${ }^{(2)}$, and it has since been applied to nuclear power plants ${ }^{(3)}$. From the point of view of avoiding damage to the peened surface and/or the component, a relatively low injection pressure is preferable. In order to optimize the injection pressure of the jet to generate cavitation impacts for peening, the residual stress of stainless steel treated by a high speed water jet at various nozzle throat diameters and injection pressures was evaluated using an X-ray diffraction method.

[DOI: 10.1299/jpes.6.63]

Copyright $@ 2012$ by JSME 
The residual stress at a surface exposed to cavitation impact has been reported using a cavitation tunnel ${ }^{(4)}$. Using ultrasonic cavitation, the residual stress at the surface of metal powders has also been reported ${ }^{(5)}$. When a high speed water jet is injected into a water filled chamber, cavitation bubbles are generated within the separation bubble in the nozzle throat and/or the shear layer around the jet at the nozzle outlet. This sort of the jet with cavitation bubbles is called a cavitating jet. The efficacy of this jet is a function of the standoff distance and there are two regions within this, one for cutting and one for peening (6). The peening method is called "cavitation shotless peening", as shot are not required, or simply called "cavitation peening". The introduction of compressive residual stress into various steels using a cavitating jet has been reported ${ }^{(1)(2)(7-14)}$. The improvement in the fatigue strength of metallic materials treated by a cavitating jet has also been reported ${ }^{(15-20)}$.

In the case of normal cavitation peening, the cavitation bubbles are generated by injecting a high speed water jet into a water filled chamber. However, this sort of cavitating jet cannot be used to treat large components outside the plant. Soyama realized a cavitating jet in air without the use of a water filled chamber by injecting a high speed water jet into a low speed water jet and directly discharging it into air, using a concentric nozzle ${ }^{(9)(21-23)}$. An optimized cavitating jet in air is more versatile than one in water ${ }^{(9)(21)(22)}$, since a cavitating jet in air can introduce compressive residual stress in the surface of components that cannot be put into a water filled chamber.

As is well known, the cavitation intensity depends on the scale of the cavitating region according to a power law ${ }^{(24)(25)}$. It has been suggested that a large cavitating jet can produce more aggressive cavitation impact compared to a small cavitating jet at a constant injection pressure. Since the aggressive intensity of the jet changes with the nozzle outlet geometry, the nozzle geometry can be optimized ${ }^{(14)}$. In order to investigate the scaling effect of the nozzle throat diameter, the nozzle outlet geometry should be considered. On the other hand, as a cavitating jet has a maximum intensity at a particular cavitation number, $\sigma=0.014^{(26)}$, the cavitation intensity of a cavitating jet with a too high injection pressure can decrease as the injection pressure is increased when the downstream pressure of the nozzle is constant.

In the present paper, in order to optimize the nozzle throat diameter and the injection pressure for cavitation peening at constant downstream pressure of the nozzle, the residual stress of stainless steel treated by a cavitating jet under various jet conditions was evaluated using an X-ray diffraction method.

\section{Experimental apparatus and procedures}

Figure 1 shows a schematic diagram of a cavitating jet with a low injection pressure of less than $30 \mathrm{MPa}$. The injection pressure of the high speed water jet, $p_{1}$, is controlled by the angular velocity of the pump's inverter motor. In order to optimize the nozzle throat diameter, $d$, and the pressure, $p_{1}$, these parameters were varied as shown in Table 1 . The nozzle used for injection pressures of less than $30 \mathrm{MPa}$ is shown in Fig. 2 (c). For $p_{1}$ from 60 - $300 \mathrm{MPa}$, a plunger pump with a pressure intensifier was used, and nozzles with diamond orifices were used as shown in Figs. 2 (a) and (b). The downstream pressure of the nozzle throat was $0.1 \mathrm{MPa}$, i.e., atmospheric pressure.

The main parameter for cavitating flow is the cavitation number, $\sigma$, which is usually defined as the ratio between the flow velocity and the pressure near the cavitating region ${ }^{(27)}$. In the case of flow through nozzles and/or orifices, the flow velocity depends on the difference between the upstream and downstream pressures of the nozzles and orifices. Thus, the cavitation number, $\sigma$, of a cavitating jet through a nozzle is given by Eq. (1):

$$
\sigma=\frac{p_{2}-p_{v}}{p_{1}-p_{2}} \cong \frac{p_{2}}{p_{1}}
$$

Where $p_{1}, p_{2}$ and $p_{v}$ are the upstream and downstream pressures, and the vapor pressure of 


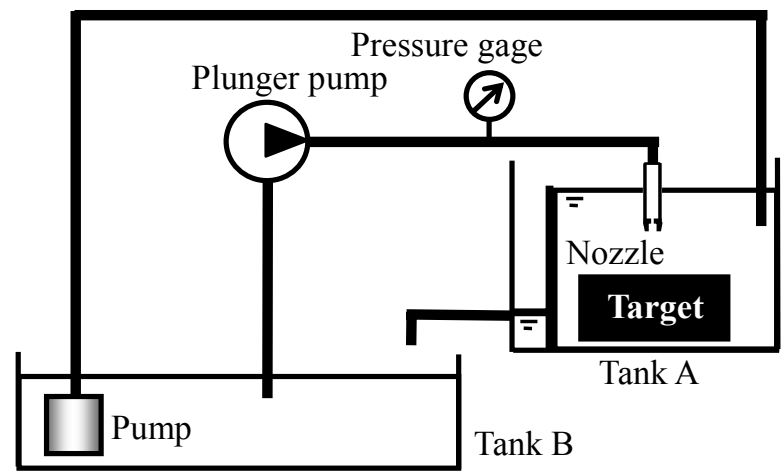

Fig. 1 Schematic diagram of cavitating jet apparatus

Table 1 Variation of nozzle throat diameter and injection pressure

\begin{tabular}{c|c|c|c}
\hline Nozzle throat diameter $d \mathrm{~mm}$ & 0.35 & 0.55 & 2 \\
\hline Discharge coefficient $C_{d}$ & 0.64 & 0.64 & 0.64 \\
\hline Effective nozzle diameter $d_{e} \mathrm{~mm}$ & 0.28 & 0.44 & 1.60 \\
\hline Injection pressure $p_{1} \mathrm{MPa}$ & 100,200, & $60,70,80$, & $5,10,20$, \\
& 300 & 90,100 & 30 \\
\hline Downstream pressure $p_{2} \mathrm{MPa}$ & 0.1 & 0.1 & 0.1 \\
\hline
\end{tabular}

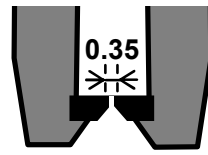

(a) Up to $p_{1}=300 \mathrm{MPa}$

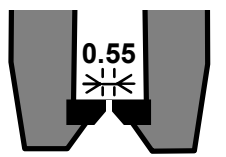

(b) $\mathrm{Up}$ to $p_{1}=100 \mathrm{MPa}$

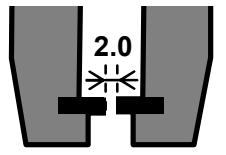

(c) $\mathrm{Up}$ to $p_{1}=30 \mathrm{MPa}$

Fig. 2 Nozzle geometry

the test water, respectively. The cavitation number is simplified in Eq. (1), because $p_{1} » p_{2}$ » $p_{v}$. The cavitating region develops as $\sigma$ decreases.

The material under test was Japanese Industrial Standards JIS SUS316L steel. The dimensions of the specimens were $200 \mathrm{~mm}$ in length, $100 \mathrm{~mm}$ in width and they were $6 \mathrm{~mm}$ thick. The cavitating jet scanned the specimen surface in the longitudinal direction. The processing time per unit length, $t_{p}$, is determined by the scanning speed, $v$, and the number of scans, $n$, as follows:

$$
t_{p}=\frac{n}{v}
$$

In order to optimize $d, p_{1}$ and $s$, which is the standoff distance between the specimen surface and the nozzle, the compressive residual stress introduced by cavitation peening was measured using an X-ray diffraction method, i.e., the $\sin ^{2} \psi$ method, employing an X-ray tube with a $\mathrm{Cr}$ target operated at $30 \mathrm{kV}$ and $8 \mathrm{~mA}$. X-rays from the $\mathrm{K} \beta$ peak were used. The angle of the soller slit was 1 degree and the slit width was $4 \mathrm{~mm}$. In this study, the diffractive plane was the (3 111 ) plane of $\gamma$-Fe, and the diffractive angle without strain $2 \theta_{0}$ was 148.5 degrees. Diffractive angle measurements from 143.5 to 153.5 degrees in steps of 0.2 degrees were made. The diffracted X-rays were counted for $3 \mathrm{sec}$. for each step using a scintillation counter at angles of $\psi=0,22.8,33.2,42.2$ and 50.8 degrees. The diffractive angle was determined by a half value width method, and the stress factor was -368.9 
$\mathrm{MPa} / \mathrm{deg}$. In order to measure the residual stress introduced by cavitation impact without the effect of water droplets at the jet center, the residual stress midway between the center of the jet and the edge of the region affected by cavitation impact was examined. The cavitation impact region was determined by coating the specimen with blue paint and exposing it to the jet to remove the paint. By this method, the width of peened area can also be determined. The area used for the X-ray diffraction measurements was $10 \mathrm{~mm} \times 3 \mathrm{~mm}$.

First, in order to optimize the standoff distance, $s$, at various $d$ and $p_{1}, s$ was varied from 30 to $160 \mathrm{~mm}$, and the specimens were treated by cavitation peening for a processing time of $1 \mathrm{~s} / \mathrm{mm}$. The standoff distance for which the maximum compressive residual stress was introduced is termed the optimum standoff distance and given the symbol $s_{\text {opt }}$. Secondly, after optimizing the standoff distance, in order to investigate the variation of compressive residual stress with processing time, $t_{p}$, for various $d$ and $p_{1}$ at $s_{\text {opt }}, t_{p}$ was varied from 0 to 10 $\mathrm{s} / \mathrm{mm}$. Measurements were again done using the X-ray diffraction method. The relationship between the residual stress, $\sigma_{r}$, and the saturated residual stress, $\sigma_{s a t}$, is given by the following equation obtained from a previous report ${ }^{(23)}$.

$$
\sigma_{r}=\sigma_{\text {sat }}\left(1-e^{-a t_{p}}\right)
$$

Where $a$ is a constant which is related to the frequency of cavitation impact. Finally, the variation of compressive residual stress with depth for each $d$ and $p_{1}$ at $t_{p}=1 \mathrm{~s} / \mathrm{mm}$ was evaluated by alternating the X-ray diffraction measurements with electropolishing.

\section{Results and discussion}

Figure 3 shows the residual stress, $\sigma_{r}$, changing with injection pressure, $p_{1}$, as a function of standoff distance normalized by the nozzle throat diameter, $s / d$, at $d=0.35,0.55$ and 2.0 $\mathrm{mm}$. The processing time, $t_{p}$, was set to $1 \mathrm{~s} / \mathrm{mm}$ in this experiment. As shown in Fig. 3 , the introduced compressive residual stress varies with $s / d$, and has a maximum value in each case. From this result, the optimum standoff distance, $s_{\text {opt }}$, can be obtained as shown in Table 2. The optimum standoff distance increases with decreasing cavitation number as shown in Fig. 4. With $d=0.35 \mathrm{~mm}$ (Fig. 3 (a)), from $p_{1}=100$ to $300 \mathrm{MPa}$, the compressive residual stress at the optimum standoff distance is almost constant with respect to injection pressure considering the standard deviation of the X-ray diffraction measurements. The maximum compressive stress is $280 \mathrm{MPa}$ at $p_{1}=300 \mathrm{MPa}$. With $d=0.55 \mathrm{~mm}$ (Fig. 3 (b)), the maximum compressive residual stress has the same tendency as with $d=0.35 \mathrm{~mm}$. Moreover, with $d=2.0 \mathrm{~mm}$ (Fig. 3 (c)), the maximum compressive residual stress is 340 $\mathrm{MPa}$ at $p_{1}=10 \mathrm{MPa}$. For short processing times, i.e., $t_{p}=1 \mathrm{~s} / \mathrm{mm}$, the maximum compressive residual stress at the surface in Fig. 3 is $340 \mathrm{MPa}$ at $p_{1}=10 \mathrm{MPa}$, which is larger than $280 \mathrm{MPa}$ at $p_{1}=300 \mathrm{MPa}$. This result indicates that using a high speed water jet at a low injection pressure provides more effective treatment than one at a high injection pressure.

In order to investigate the relationship between the optimum standoff distance shown in Table 2 and the cavitation number, which is main parameter for cavitating flow, Fig. 4 shows the optimum standoff distance normalized by effective diameter of the nozzle, $s_{\text {opt }} /$ $d_{e}$, as a function of the cavitation number, $\sigma$, obtained using Eq. (1) with $d=0.35,0.55$ and $2.0 \mathrm{~mm}$. The normalized optimum standoff distance, $s_{\text {opt }} / d_{e}$, is proportional to $\sigma^{-0.5}, \sigma^{-0.8}$ and $\sigma^{-0.4}$ for $d=0.35,0.55$ and $2.0 \mathrm{~mm}$, respectively. Thus, parameters of the cavitating jet such as $S_{\text {opt }}$ can be determined from the cavitation number, $\sigma$.

Figure 5 shows the residual stress, $\sigma_{r}$, introduced at the optimum standoff distance as a function of processing time per unit length, $t_{p}$, at various injection pressures, $p_{1}$. As shown in Fig. 5, in each case, the compressive residual stress at the surface increases rapidly until $t_{p}=2 \mathrm{~s} / \mathrm{mm}$, and then increases more slowly before becoming almost saturated after $4 \mathrm{~s} / \mathrm{mm}$. Although the saturated compressive residual stress is nearly the same from $d=0.35$ to 2.0 $\mathrm{mm}$, except for the case of $p_{1}=30 \mathrm{MPa}$ with $d=0.35 \mathrm{~mm}$, there is a difference which depends on $p_{1}$ at short processing time. In the case of $p_{1}=10 \mathrm{MPa}$ with $d=2.0 \mathrm{~mm}$, high compressive residual stress is introduced more quickly at the surface than for other values of $d$ and $p_{1}$. 


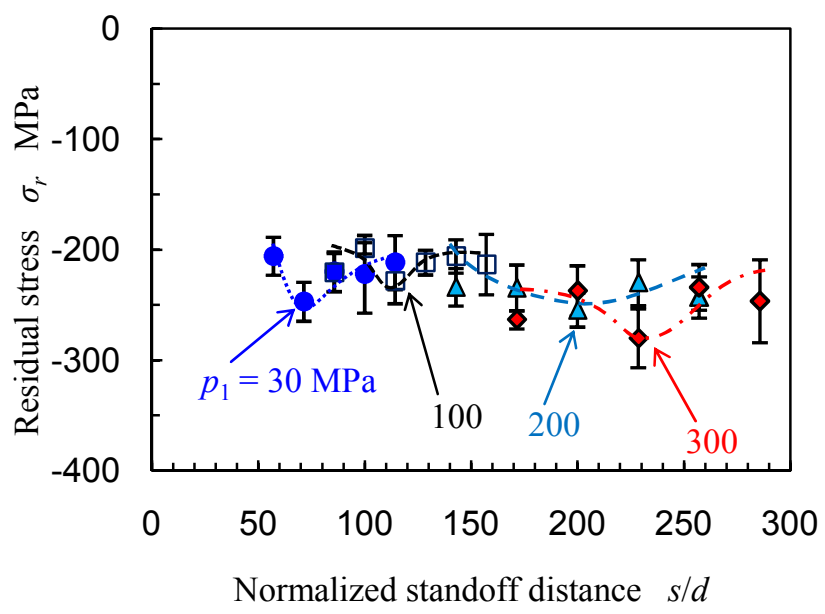

(a) $d=0.35 \mathrm{~mm}$

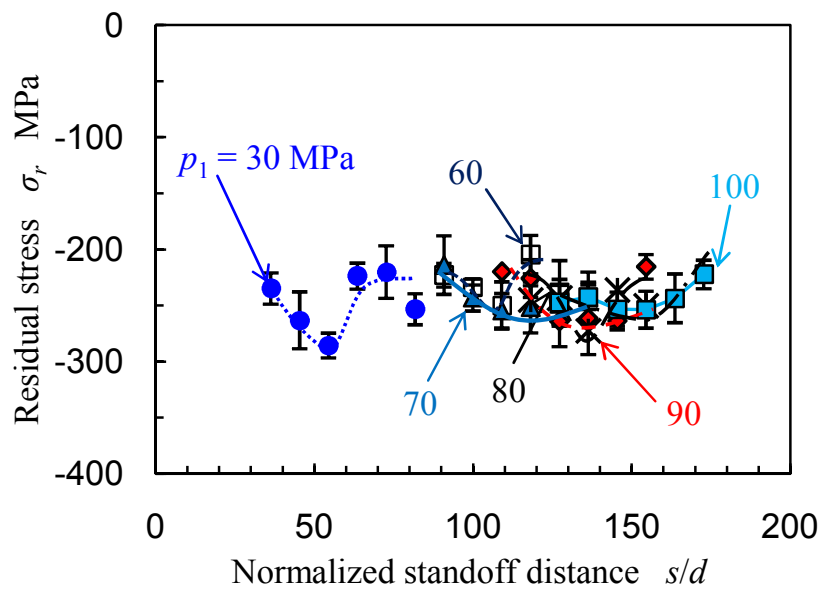

(b) $d=0.55 \mathrm{~mm}$

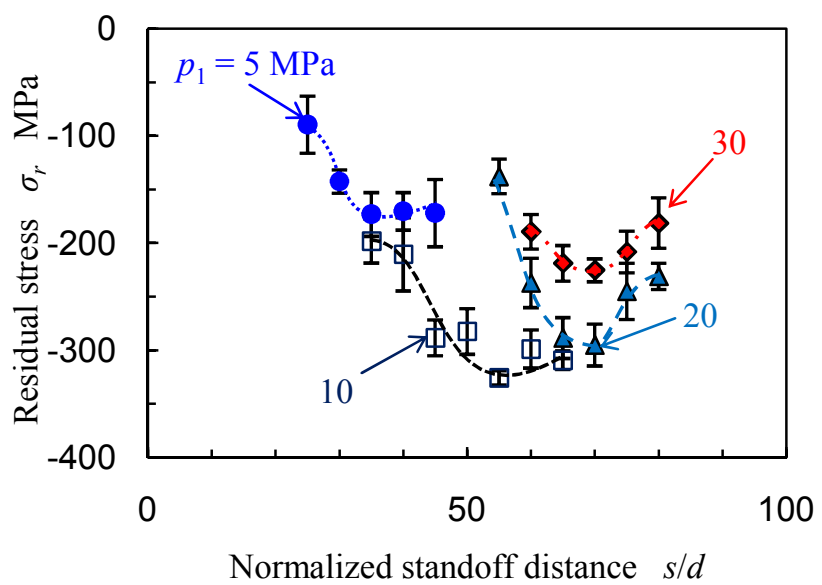

(c) $d=2.0 \mathrm{~mm}$

Fig. 3 Variation of compressive residual stress with normalized standoff distance at different injection pressures for each nozzle throat diameter $\left(t_{p}=1 \mathrm{~s} / \mathrm{mm}\right)$ 
Table 2 Optimum standoff distance $s_{\text {opt }}$ in $\mathrm{mm}$ for various conditions of the nozzle throat diameter and injection pressure

\begin{tabular}{c|c|c|c}
\hline \multirow{2}{*}{$\begin{array}{c}\text { Injection } \\
\text { pressure } p_{1} \mathrm{MPa}\end{array}$} & \multicolumn{3}{|c}{ Nozzle throat diameter $d \mathrm{~mm}$} \\
\cline { 2 - 4 } & 0.35 & 0.55 & 2.0 \\
\hline 5 & - & - & 70 \\
\hline 10 & - & - & 110 \\
\hline 20 & - & - & 140 \\
\hline 30 & 30 & 30 & 140 \\
\hline 60 & - & 60 & - \\
\hline 70 & - & 60 & - \\
\hline 80 & - & 70 & - \\
\hline 90 & - & 75 & - \\
\hline 100 & 40 & 85 & - \\
\hline 200 & 70 & - & - \\
\hline 300 & 80 & - & - \\
\hline & & & \\
\hline
\end{tabular}

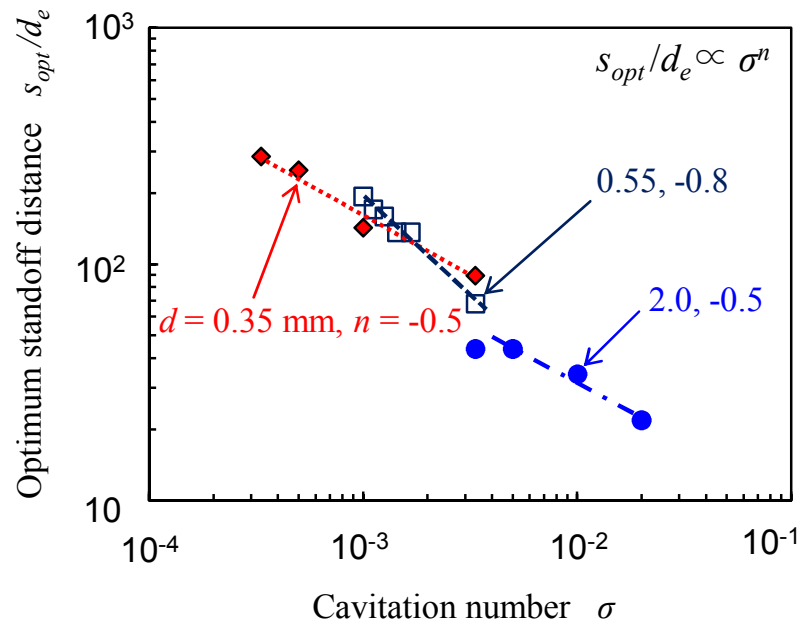

Fig. 4 Relationship between optimum standoff distance and cavitation number

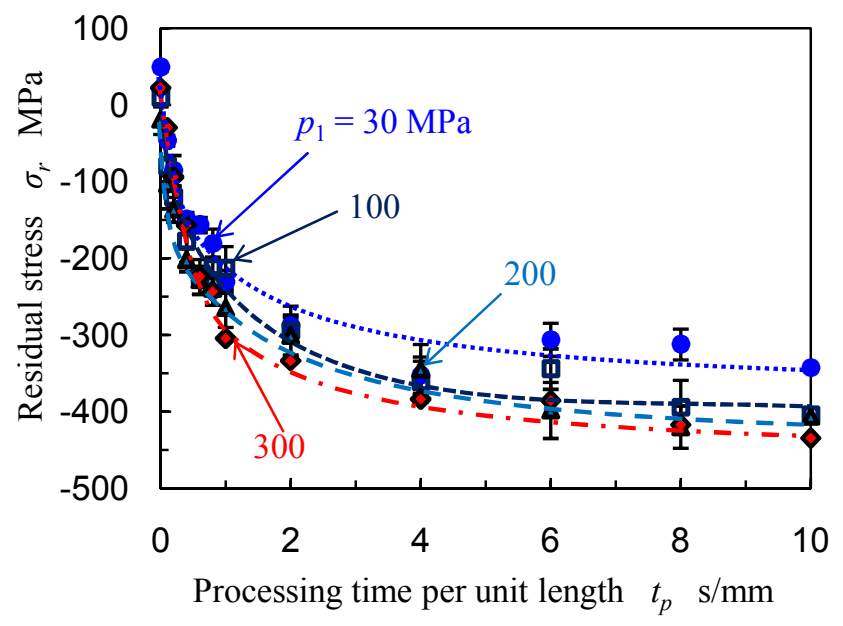

(a) $d=0.35 \mathrm{~mm}$

Fig. 5 Variation with processing time per unit length of the compressive residual stress introduced at the surface at the optimum standoff distance 


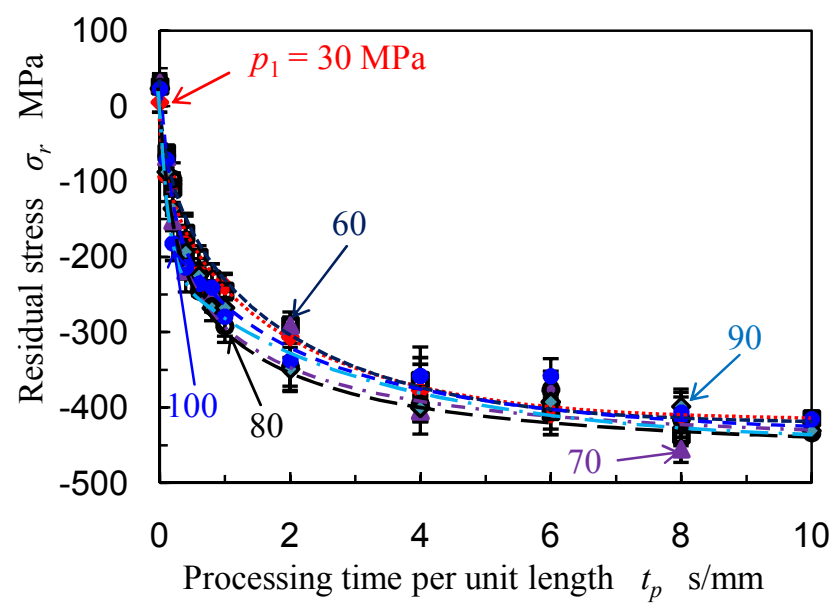

(b) $d=0.55 \mathrm{~mm}$

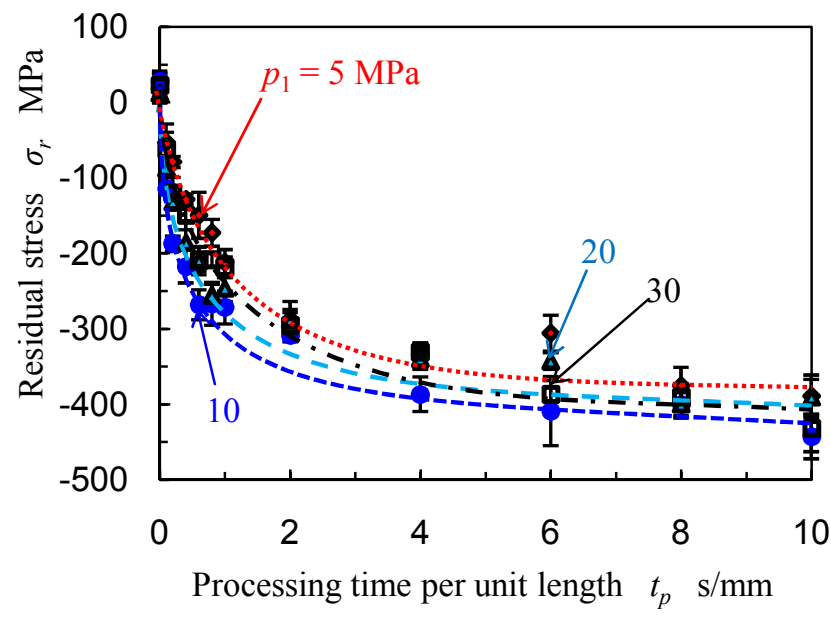

(c) $d=2.0 \mathrm{~mm}$

Fig. 5 Variation with processing time per unit length of the compressive residual stress introduced at the surface at the optimum standoff distance (Continued)

In order to display the relationship between the compressive residual stress and injection pressure for short processing time and sufficient processing time, Figs. 6 (a), (b) and (c) show the residual stress, $\sigma_{r}$, for $t_{p}=1 \mathrm{~s} / \mathrm{mm}$ and the saturated residual stress $\sigma_{s a t}$ and constant number $a$ obtained using Eq. (3) as a function of injection pressure $p_{1}$. For the short processing time, shown in Fig. 6 (a), the compressive residual stress varies with injection pressure. With $d=2.0 \mathrm{~mm}$, it varies drastically with increasing injection pressure compared to the cases with $d=0.35$ and $0.55 \mathrm{~mm}$, and it has a maximum compressive residual stress of $340 \mathrm{MPa}$ at $p_{1}=10 \mathrm{MPa}$. At sufficient processing times as shown in Fig. 6 (b), the compressive residual stress is almost constant with increasing injection pressure, and constant number a, which means the speed to the saturated value, has a maximum at $p_{1}$ $=10 \mathrm{MPa}$ and $d=2.0 \mathrm{~mm}$ as shown in Fig. 6 (c). From these results, it seems that the most effective injection pressure and nozzle throat diameter for introducing compressive residual stress at the surface are $p_{1}=10 \mathrm{MPa}$ and $d=2.0 \mathrm{~mm}$, respectively.

In order to consider why the compressive residual stress has a maximum at $p_{1}=10 \mathrm{MPa}$ in Fig. 6 (a), the residual stress as a function of cavitation number, $\sigma$, is illustrated in Fig. 7. Obviously, the residual stress has a maximum at $\sigma=0.01$, i.e., $p_{1}=10 \mathrm{MPa}$. As the capability of the jet to introduce compressive residual stress corresponds to the capability to generate mass loss at metal surface, i.e., erosion, since both the compressive residual stress and erosion result from plastic deformation pits induced by the impacts generated when cavitation bubbles collapsing. It has been reported that the maximum capability of the jet is at $\sigma=0.01$ or 0.014 at constant injection pressure demonstrated by erosion test ${ }^{(2)(28)}$. The 
jet power, which is defined by the product of the injection pressure and the flow rate, increases from $p_{1}=10 \mathrm{MPa}$ to $20 \mathrm{MPa}$. However, the cavitation number decreases from 0.01 to 0.005 . This means that the injection pressure increases but the capability of the jet is

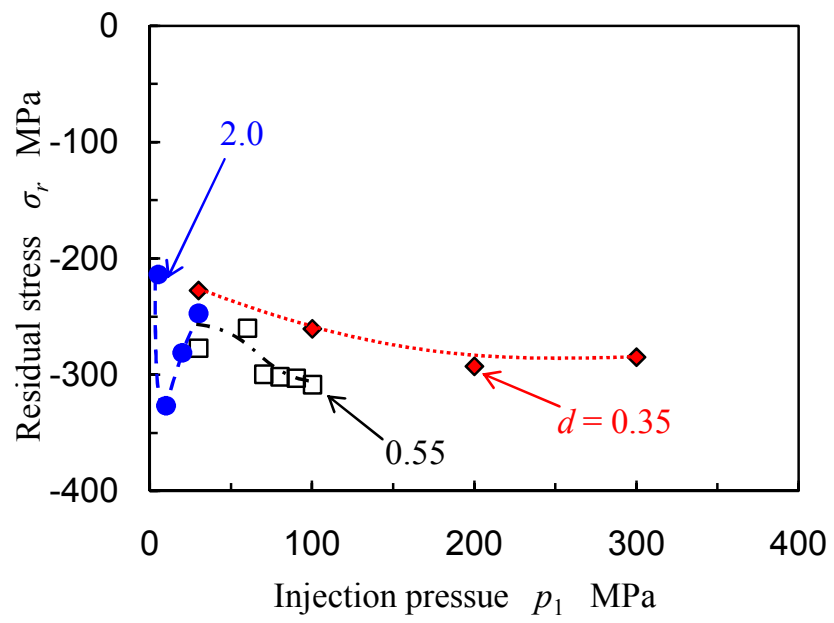

(a) $\sigma_{r}$ at $t_{p}=1 \mathrm{~s} / \mathrm{mm}$

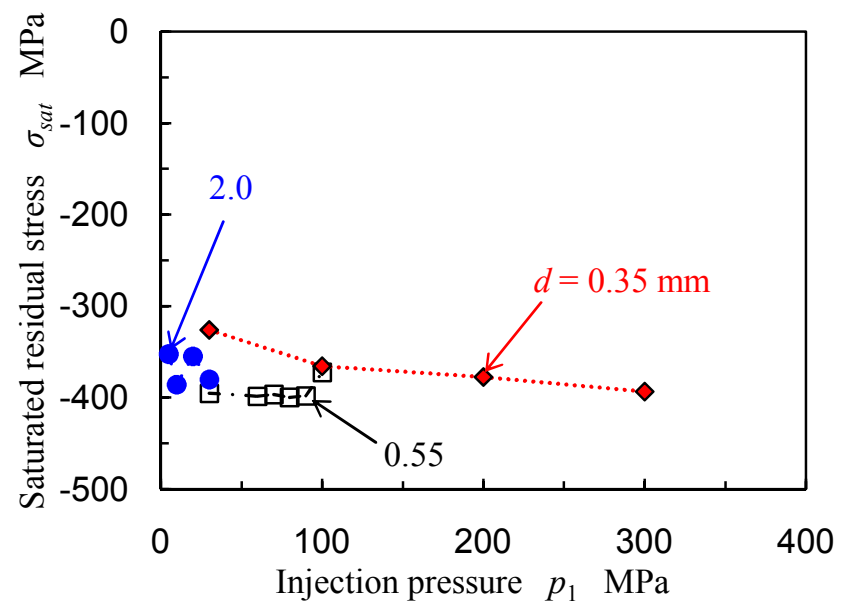

(b) $\sigma_{\text {sat }}$ obtained by Eq. (3)

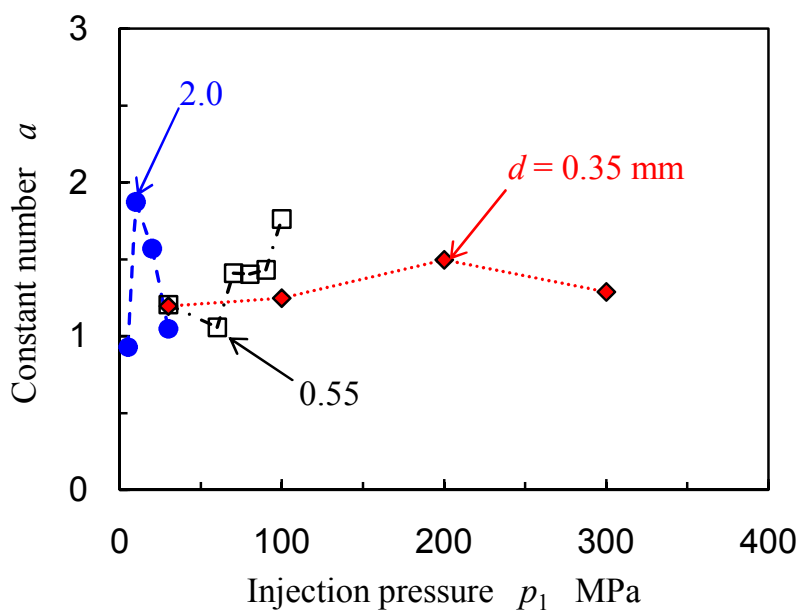

(c) $a$ obtained by Eq. (3)

Fig. 6 Relationship between compressive residual stress introduced at the surface and injection pressure 


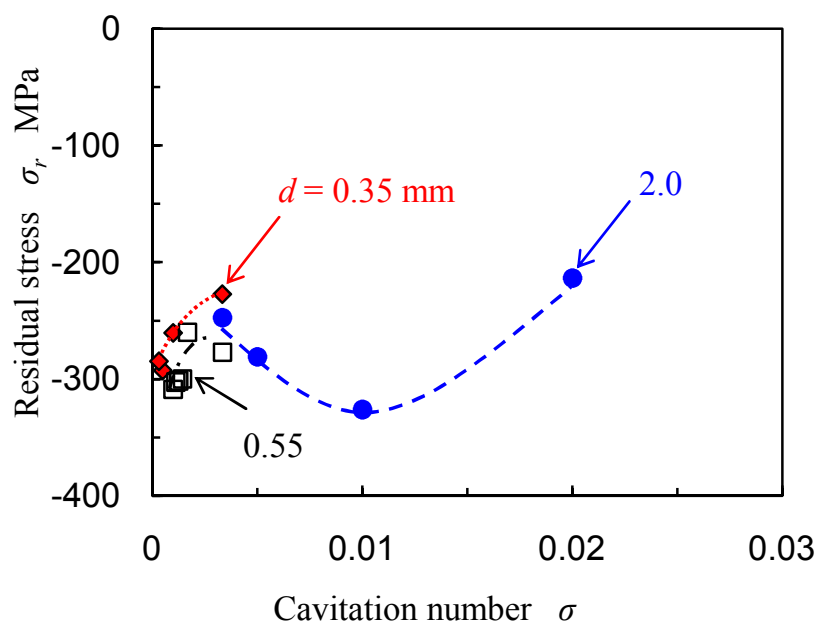

Fig. 7 Relationship between compressive residual stress introduced at the surface and cavitation number $\left(t_{p}=1 \mathrm{~s} / \mathrm{mm}\right)$

reduced because of the decrease in cavitation number. As a result, from the point of view of introducing compressive residual stress into stainless steel, the capability of the cavitating jet has a maximum at $p_{1}=10 \mathrm{MPa}$.

Figure 8 shows the residual stress, $\sigma_{r}$, at $t_{p}=1 \mathrm{~s} / \mathrm{mm}$ as a function of jet power, $P$, computed by multiplying the injection pressure by the flow rate. Although the introduced compressive residual stress varies monotonically with increasing jet power in the case of $d$ $=0.35$ and $0.55 \mathrm{~mm}$, it has a maximum value at $P=3 \mathrm{~kW}$, i.e., $p_{1}=10 \mathrm{MPa}, \sigma=0.01$, for the case of $d=2.0 \mathrm{~mm}$.

In order to investigate the efficiency of cavitation peening, not only for its capacity to introduce compressive residual stress, but also for the width of the treatment area in real applications, Figs. 9 (a) and (b) show the product of the residual stress and the width of the treatment area, $\left|\sigma_{r} \times w\right|$ as functions of the injection pressure, $p_{1}$, and the jet power, $P$, respectively, with $d=0.35,0.55$ and $2.0 \mathrm{~mm}$. $w$ is defined by the removal of region of the blue paint. As shown in Fig. 9 (a), the parameter $\left|\sigma_{r} \times w\right|$, which is related to the efficiency of cavitation peening, increases with increasing injection pressure, and then almost saturates at a value of $10 \mathrm{MPa} \cdot \mathrm{m}$ at $p_{1}=200 \mathrm{MPa}$ for $d=0.35 \mathrm{~mm}$ and at a value of $15 \mathrm{MPa} \cdot \mathrm{m}$ at $p_{1}$ $=20 \mathrm{MPa}$ for $d=2.0 \mathrm{~mm}$. The compressive residual stress introduced at the surface is independent of injection pressure as shown in Fig. 6. The reason for the increase in $\left|\sigma_{r} \times w\right|$ with increasing injection pressure is the increase in the width treated by increasing the injection pressure. In Fig. 9 (b), $\left|\sigma_{r} \times w\right|$ with $d=0.35$ and $0.55 \mathrm{~mm}$ have the same tendency, and are smaller than that with $d=2.0 \mathrm{~mm}$ at the same jet power. From the point of view of introducing compressive residual stress at the surface, these results indicate that using the conditions of $d=2.0 \mathrm{~mm}$ and $p_{1}=10$ or $20 \mathrm{MPa}$ provides more effective treatment than those of $d=0.35 \mathrm{~mm}$ and $p_{1}=200$ or $300 \mathrm{MPa}$.

The distribution of residual stress introduced by cavitation peening as a function of depth with various nozzle throat diameters and injection pressures at $t_{p}=1 \mathrm{~s} / \mathrm{mm}$ was also investigated. Figure 10 shows the residual stress, $\sigma_{r}$, obtained using X-ray diffraction measurements, as a function of depth, $z$. The measurements were alternated with electropolishing to enable the measurements to be made at various depths. Although the compressive residual stress at the surface is almost the same and decreases with increasing $z$ in each case, there is a difference in gradient between them. The thickness of the residual stress layer with $d=2.0 \mathrm{~mm}$ and $p_{1}=10-30 \mathrm{MPa}$ is about $600 \mu \mathrm{m}$, and this is greater than that with $d=0.35 \mathrm{~mm}$ and $p_{1}=300 \mathrm{MPa}$ and with $d=0.55$ and $p_{1}=100 \mathrm{MPa}$ which are about $400 \mu \mathrm{m}$.

As a whole, a higher compressive residual stress can be introduced more deeply with $d=2.0$ $\mathrm{mm}$ and $p_{1}=10 \mathrm{MPa}$ than with $d=0.35 \mathrm{~mm}$ and $p_{1}=300 \mathrm{MPa}$, and a cavitating jet with a lower injection pressure can produce more aggressive cavitation impacts compared to that with a higher injection pressure. This indicates that the cavitating jet generated by the high speed water 
jet at low injection pressure with a wide nozzle throat is more effective than one generated by a jet at a high injection pressure with a narrow nozzle. Considering the injection power, the cavitating jet generated by a jet at lower pressure is far superior for cavitation peening.

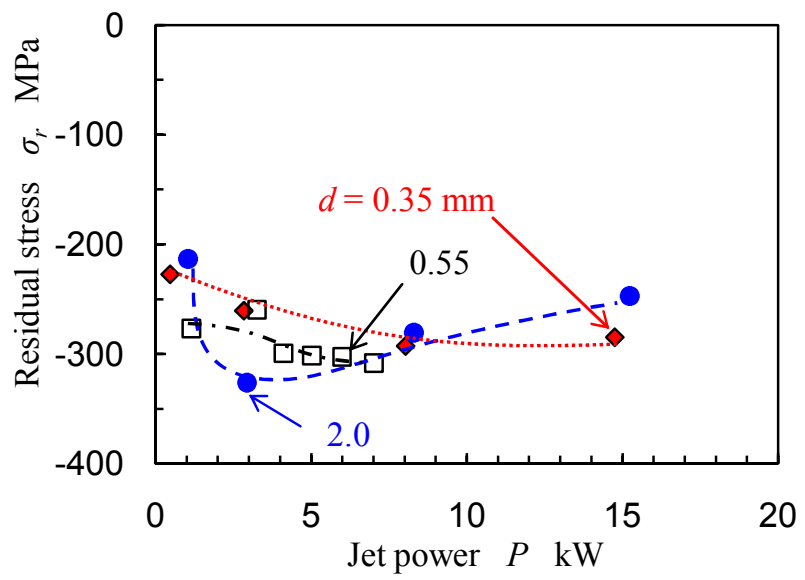

Fig. 8 Relationship between compressive residual stress introduced at the surface and jet power $\left(t_{p}=1 \mathrm{~s} / \mathrm{mm}\right)$

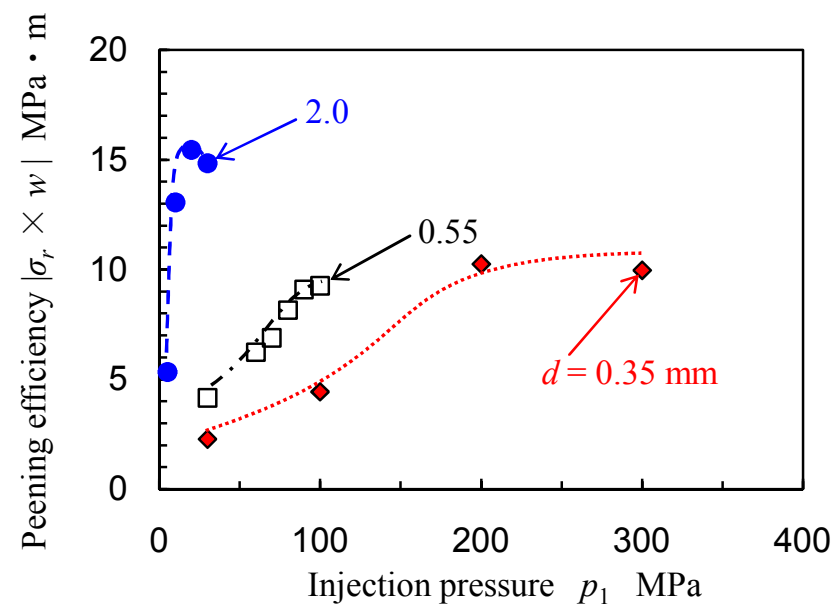

(a) Injection pressure

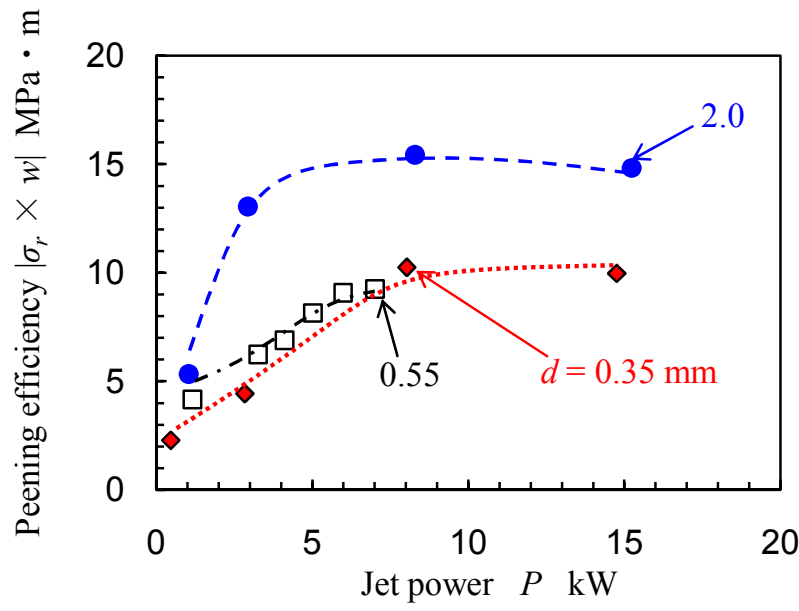

(b) Jet power

Fig. 9 Variation of the efficiency of cavitation peening with injection pressure and jet power $\left(t_{p}=1 \mathrm{~s} / \mathrm{mm}\right)$ 


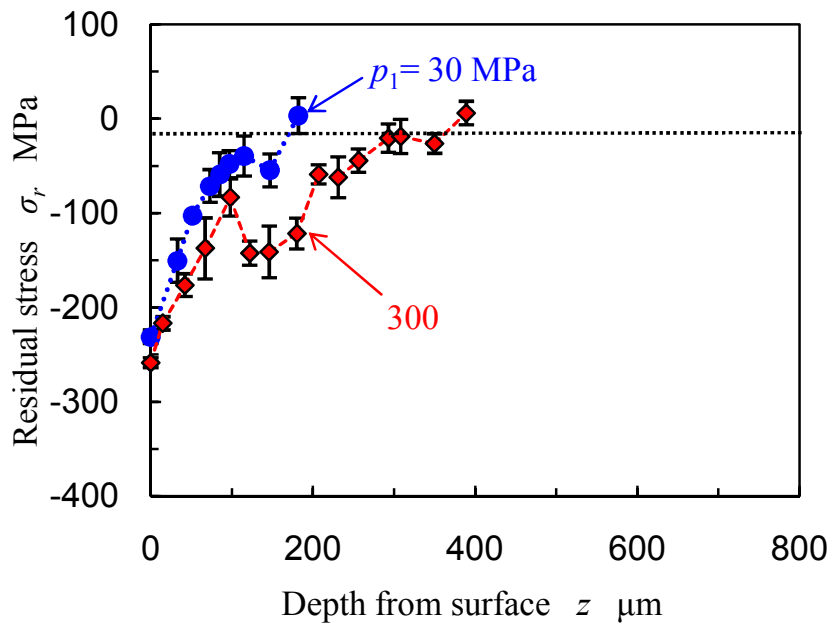

(a) $d=0.35 \mathrm{~mm}$

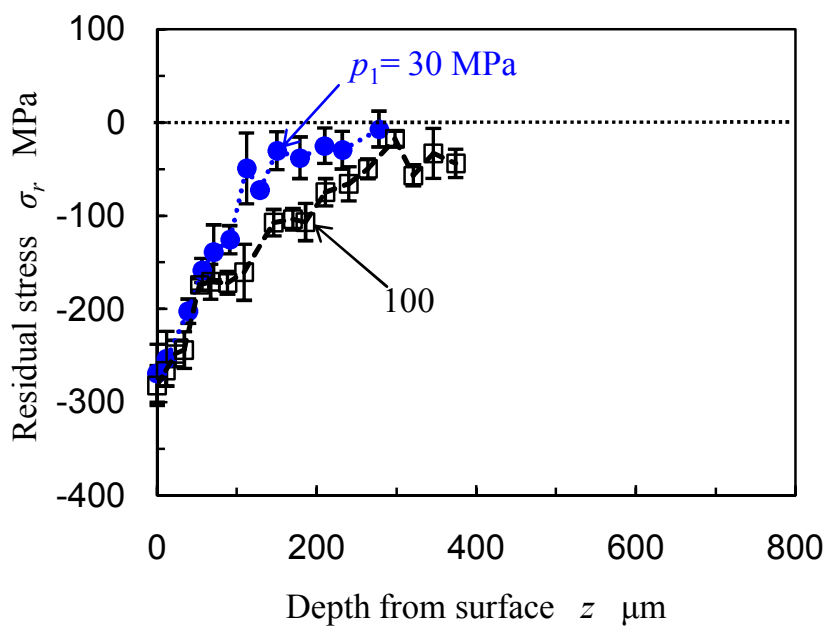

(b) $d=0.55 \mathrm{~mm}$

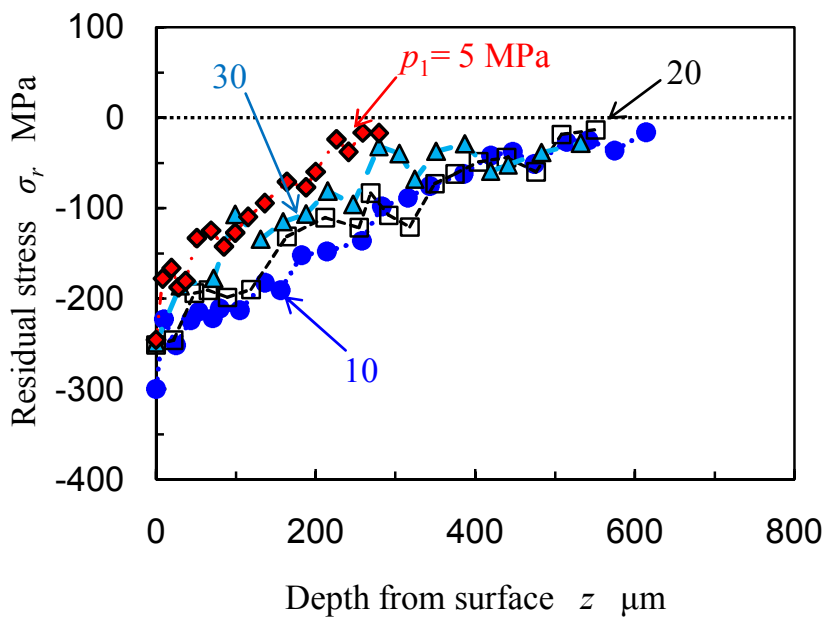

(c) $d=2.0 \mathrm{~mm}$

Fig. 10 Variation of residual stress with depth $\left(t_{p}=1 \mathrm{~s} / \mathrm{mm}\right)$ 


\section{Conclusion}

In order to examine the aggressive intensity of a cavitating jet, the compressive residual stress introduced by cavitation peening was evaluated by an X-ray diffraction method. To maximize the aggressive intensity, the nozzle throat diameter, $d$, and injection pressure, $p_{1}$, were varied at constant downstream pressure of the nozzle. The material under test was JIS SUS316L steel. It was found that a low injection pressure, i.e., $p_{1}=10 \mathrm{MPa}$ with $d=2.0$ $\mathrm{mm}$, introduced a greater compressive residual stress over a wider area of the surface than a high injection pressure i.e., $p_{1}=300 \mathrm{MPa}$ with $d=0.35 \mathrm{~mm}$. Moreover, the depth of introduced compressive residual stress with $d=2.0 \mathrm{~mm}$ and $p_{1}=10 \mathrm{MPa}$ was about $600 \mu \mathrm{m}$ deep, which is $50 \%$ more than with $d=0.35 \mathrm{~mm}$ and $p_{1}=300 \mathrm{MPa}$, which was $400 \mu \mathrm{m}$.

\section{Acknowledgments}

This work was partly supported by the Japan Society for the Promotion of Science under the Grant-in-aid for Scientific Research (A) 20246030 and Research Fellow 22.2438, and The Cannon Foundation.

\section{References}

(1) Soyama, H., Yamauchi, Y., Ikohagi, T., Oba, R., Sato, K., Shindo, T. and Oshima, R., Marked Peening Effects by High-Speed Submerged-Water-Jets, Journal of Jet Flow Engineering, Vol. 13 (1996), pp. 25-32.

(2) Hirano, K., Enomoto, K., Hayashi, E. and Kurosawa, K., Effects of Water Jet Peening on Corrosion Resistance and Fatigue Strength of Type 304 Stainless Steel, Journal of the Society of Materials Science, Vol. 45 (1996), pp. 740-745.

(3) Saitou, N., Enomoto, K., Kurosawa, K., Morinaka, R., Ishikawa, T. and Yoshimura, T., Development of Water Jet Peening Technique for Reactor Internal Components of Nuclear Power Plant, Journal of Jet Flow Engineering, Vol. 20 (2003), pp. 4-12.

(4) Blickwedel, H., Haferkamp, H., Louis, H. and Tai, P. T., Modification of Material Structure by Cavitation and Liquid Impact and Their Influence on Mechanical Properties, Proceedings of the 7th International Conference on Erosion by Liquid and Solid Impact, (1987), pp. 31-1-31-6.

(5) Rawers, J. C., McCune, R. A. and Dunning, J. S., Ultrasound Treatment of Centrifugally Atomized 316 Stainless Steel Powders, Metallurgical and Materials Transactions A, Vol. 22 (1991), pp. 3025-3033.

(6) Yamauchi, Y., Soyama, H., Adachi, Y., Sato, K., Shindo, T., Oba, R., Oshima, R. and Yamabe, M., Suitable Region of High-Speed Submerged Water Jets for Cutting and Peening, JSME International Journal, Series B, Vol. 38 (1995), pp. 31-38.

(7) Soyama, H., Park, J.D. and Saka, M., Use of Cavitating Jet for Introducing Compressive Residual Stress, Transactions of the ASME, Journal of Manufacturing Science and Engineering, Vol. 122 (2000), pp. 83-89.

(8) Soyama, H., Sasaki, K., Odhiambo, D. and Saka, M., Cavitation Shotless Peening for Surface Modification of Alloy Tool Steel, JSME International Journal, Series A, Vol. 46 (2003), pp. 398-402.

(9) Soyama, H., Introduction of Compressive Residual Stress Using a Cavitating Jet in Air, Transactions of the ASME, Journal of Engineering Materials and Technology, Vol. 126 (2004), pp. 123-128.

(10) Soyama, H., Macodiyo, D.O. and Mall, S., Compressive Residual Stress into Titanium Alloy Using Cavitation Shotless Peening Method, Tribology Letters, Vol. 17 (2004), pp. 501-504.

(11) Qin, M., Ju, D.Y. and Oba, R., Investigation of the Influence of Incidence Angle on the Process Capability of Water Cavitation Peening, Surface and Coatings Technology, Vol. 
201 (2006), pp. 1409-1413.

(12) Grinspan, A.S. and Gnanamoorthy, R., Effect of Nozzle-Traveling Velocity on Oil Cavitation Jet Peening of Aluminum Alloy, AA 6063-T6 2007, Transactions of the ASME, Journal of Engineering Materials Technology, Vol. 129 (2007), pp. 609-613.

(13) Soyama, H., Sekine, Y. and Oyama, Y., Improvement of the Fatigue Strength of Stainless Steel SUS316L by a Cavitating Jet with an Associated Water Jet in Water, ISIJ International, Vol. 48 (2008), pp. 1577-1581.

(14) Soyama, H. and Takakuwa, O., Enhancing the Aggressive Strength of a Cavitating Jet and Its Practical Application, Journal of Fluid Science and Technology, Vol. 6 (2011), pp. 510-521.

(15) Soyama, H., Improvement in Fatigue Strength of Silicon Manganese Steel SUP7 by Using a Cavitating Jet, JSME International Journal, Series A, Vol. 43 (2000), pp. 173-178.

(16) Soyama, H., Kusaka, T. and Saka, M., Peening by the Use of Cavitation Impacts for the Improvement of Fatigue Strength, Journal of Materials Science Letters, Vol. 20 (2001), pp. 1263-1265.

(17) Soyama, H., Saito, K. and Saka, M., Improvement of Fatigue Strength of Aluminum Alloy by Cavitation Shotless Peening, Transaction of the ASME, Journal of Engineering Materials and Technology, Vol. 124 (2002), pp. 135-139.

(18) Odhiambo, D. and Soyama, H., Cavitation Shotless Peening for Improvement of Fatigue Strength of Carbonized Steel, International Journal of Fatigue, Vol. 25 (2003), pp. 1217-1222.

(19) Soyama, H., Shimizu, M., Hattori, Y. and Nagasawa, Y., Improving the Fatigue Strength of the Elements of a Steel Belt for CVT by Cavitation Shotless Peening, Journal of Materials Science, Vol. 43 (2008), pp. 5028-5030.

(20) Soyama, H. and Sekine Y., Sustainable Surface Modification Using Cavitation Impact for Enhancement of Fatigue Strength Demonstrated by a Power Circulating Type Gear Tester, International Journal of Sustainable Engineering, Vol. 3 (2010), pp. 25-32.

(21) Soyama, H., High-Speed Observation of a Cavitating Jet in Air, Transactions of the ASME, Journal of Fluids Engineering, Vol. 127 (2005), pp. 1095-1101.

(22) Soyama, H., Improvement of Fatigue Strength by Using Cavitating Jets in Air and Water, Journal of Materials Science, Vol. 42 (2007), pp. 6638-6641.

(23) Soyama, H., Kikuchi, T., Nishikawa, M. and Takakuwa, O., Introduction of Compressive Residual Stress into Stainless Steel by Employing a Cavitating Jet in Air, Surface and Coatings Technology, Vol. 205 (2011), pp. 3167-3174.

(24) Soyama, H., Scaling Effect on Cavitation Erosion Pits, Transactions of the JSME, Series B, Vol. 58 (1992), pp. 3366-3372.

(25) Soyama, H. and Futakawa, M., Estimation of Cavitation Intensity from the Time Taken for Bubbles to Develop, Tribology Letters, Vol. 23 (2006), pp. 23-26.

(26) Soyama, H., Material Testing and Surface Modification by Using Cavitating Jet, Journal of the Society of Materials Science, Vol. 47 (1998), pp. 381-387.

(27) Brennen, C.E., Cavitation and Bubble Dynamics, Oxford University Press, (1995).

(28) Shimizu, S., Tanioka, K. and Ikegami, N., Erosion Induced by Ultra High Speed Cavitating Jet, Proceedings of Spring Meeting of Hydraulics \&Pneumatics, (1997), pp. 5-8. 